\title{
Synergistic effects of cinnamaldehyde in combination with eugenol against wood decay fungi
}

\author{
Tsair-Bor Yen ${ }^{\mathrm{a}}$, Shang-Tzen Chang ${ }^{\mathrm{b}, *}$ \\ a Department of Tropical Agriculture and International Cooperation, National Pingtung University of Science and Technology, Pingtung 912, Taiwan \\ b School of Forestry and Resource Conservation, National Taiwan University, Taipei 106, Taiwan
}

Received 28 August 2006; received in revised form 17 November 2006; accepted 20 November 2006

Available online 28 December 2006

\begin{abstract}
The combined effects of using cinnamaldehyde with catechin, quercetin or eugenol against wood decay fungi were examined by comparing their isoeffective concentrations to that of individual compound. Among all combinations, cinnamaldehyde with eugenol revealed the strongest synergy against Laetiporus sulphureus. The synergism was due to the interference of fungal cell wall synthesis and cell wall destruction plus radical scavenging effect. Results also suggested that antioxidant with fungicidal effect might be a better candidate than pure antioxidant for the system of fungicide/antioxidant.
\end{abstract}

(C) 2006 Elsevier Ltd. All rights reserved.

Keywords: Antifungal activity; Antioxidant; Synergy; Cinnamaldehyde; Eugenol

\section{Introduction}

Wood is widely used for a variety of purposes in both indoor and outdoor applications, but as a natural organic material, wood is susceptibly degraded by many organisms. To counter fungal decay, wood products are often treated with preservatives. The traditional wood preservatives such as creosote and inorganic preservative "chromate copper arsenate" (CCA-type C) are highly effective in protecting wood, however, they have been strictly limited their use due to their toxicity, causing serious environmental hazards. Hence, developing the environment-friendly wood preservatives to replace the traditional wood preservatives becomes an imperative issue.

It has also been postulated that wood extractives can protect heartwood via at least three different mechanisms, namely fungicidal activity, free radical scavenging/antioxidation and metal chelation (Schultz and Nicholas, 2000). Schultz and Nicholas (2002) reported that combining

\footnotetext{
* Corresponding author. Tel.: +8862 3366 4626; fax: +8862 23654520 . E-mail address: peter@ntu.edu.tw (S.-T. Chang).
}

butylated hydroxytoluene (BHT) or propyl gallate, with various organic biocides could enhance the antifungal effects. Recently, Mabicka et al. (2005) demonstrated that using 2-HPNO with either Irganox 1076 or EDTA resulted in significant synergism against a white-rot fungus. Study conducted by Hsu et al. (2007) also showed that the antifungal activities of octyl gallate were synergistically enhanced by cinnamaldehyde against various wood decay fungi.

Cinnamaldehyde, a major constituent of cinnamon essential oils, occurs naturally in the bark and leaves of cinnamon trees of the genus Cinnamomum. It has been proven to have strong antifungal activities against wide variety of wood decay fungi (Wang et al., 2005; Cheng et al., 2006), and is a potential candidate for effective and environmentally-benign wood preservatives. As for antioxidants, catechin and quercetin have been reported to process some antifungal activities (Hirasawa and Takada, 2004). Furthermore, eugenol has been demonstrated as an excellent fungicide against wood decay fungi (Wang et al., 2005). To our best knowledge, there is no report on the antifungal activities against wood decay fungi using the combination of cinnamaldehyde with natural antioxidants such as cate- 
chin, quercetin or eugenol. Therefore, the combining effects of using cinnamaldehyde with catechin, quercetin or eugenol against wood decay fungi were investigated in this study.

\section{Methods}

\subsection{Fungal strains}

The fungal strains used were white-rot fungus, Lenzites betulina (BCRC 35296) and brown-rot fungus, Laetiporus sulphureus (BCRC 35305). They were obtained from the Bioresource Collection and Research Center (BCRC) of the Food Industry Research and Development Institute (Taiwan).

\subsection{Chemicals}

1-Diphenyl-2-picrylhydrazyl (DPPH) and ascorbic acid were purchased from Sigma Chemical Co. (USA). Cinnamaldehyde, eugenol, catechin and quercetin were purchased from ACROS (Belgium).

\subsection{Free radical scavenging activity}

The scavenging activity of DPPH free radical was determined using the method reported by Guo et al. (2001). Antioxidants over a range of concentrations dissolved in ethanol $(50 \mu \mathrm{l})$ were mixed with $1000 \mu \mathrm{l}$ of $0.1 \mathrm{mM}$ DPPH-ethanol solution and $450 \mu \mathrm{l}$ of $50 \mathrm{mM}$ Tris- $\mathrm{HCl}$ buffer ( $\mathrm{pH}$ 7.4). Pure ethanol $(50 \mu \mathrm{l})$ was used as the control for this experiment. After 30 min of incubation at ambient temperature, the reduction of the DPPH free radical was measured by reading the absorbance at $517 \mathrm{~nm}$ of resulting solution. The lower the absorbance at $517 \mathrm{~nm}$ represents the higher DPPH scavenging activity. Ascorbic acid was used as the positive control and the percentage of DPPH scavenging activity is expressed by the following equation:

$\%$ Inhibition $=[1-($ absorbance of test sample

$$
\text { /absorbance of control) }] \times 100
$$

\subsection{Antifungal assays}

Antifungal assays were performed as described previously (Chang et al., 2000) with slight modifications. Cinnamaldehyde, catechin, quercetin, eugenol and propiconazole were dissolved in ethanol. Solutions of serial concentrations of chemicals were mixed with sterilized potato dextrose agar (PDA) in Petri dish $(9 \mathrm{~cm}$ dia.) containing $15 \mathrm{ml}$ agar. After inoculating the mycelia of fungus onto the center of agar, the dishes were incubated in the dark at $26 \pm 2{ }^{\circ} \mathrm{C}$ and $70 \%$ relative humidity. When the mycelium of fungi reached the edges of the control dishes, the antifungal indices were calculated as follows:

Antifungal index $\%=\left(1-D_{\mathrm{a}} / D_{\mathrm{b}}\right) \times 100$ where $D_{\mathrm{a}}$ is the diameter of growth zone in the experimental dish $(\mathrm{cm})$ and $D_{\mathrm{b}}$ is the diameter of growth zone in the control dish $(\mathrm{cm})$. The $\mathrm{IC}_{50}$ values (the concentration inhibited $50 \%$ of the mycelium growth) were calculated by probit analysis. Minimal inhibitory concentrations (MICs) were also examined using the methods reported by Kubo and Lee (1998) with slight modifications. The testing dishes were incubated under the same growth conditions as above. When the mycelium of fungi reached the edges of the control dishes, the lowest concentration with no sign of growth was defined as MIC. After the MIC was determined, a small piece of agar $\left(2 \times 2 \times 2 \mathrm{~mm}^{3}\right)$ was taken from the colony of the MIC plate, and was inoculated on a drug-free PDA medium. After 5 days, minimum fungicidal concentrations (MFCs) were determined by the lowest concentration of the test compounds in which no recovery of microorganism was observed.

\subsection{Statistical analyses}

All results were expressed as mean $\pm \mathrm{SE}(n=5)$. The significance of difference among individual mean was determined by Scheffe's multiple comparison procedure in SPSS. Results with $P<0.05$ were considered to be statistically significant difference.

\section{Results and discussion}

\subsection{Free radical scavenging activity of antioxidants}

The free radical has been proposed to be one of the decay mechanisms by fungi (Schultz and Nicholas, 2002). Therefore, the DPPH assay was used to evaluate the relationship between radical scavenging and antifungal activities. The free radical scavenging activities of cinnamaldehyde, catechin, quercetin and eugenol were determined by $\mathrm{DPPH}$ assay. The $\mathrm{EC}_{50}$ values of cinnamaldehyde, catechin, quercetin and eugenol were $>500,5.4,31.5$ and $10.3 \mu \mathrm{g} / \mathrm{ml}$, respectively. Catechin showed the strongest free radical scavenging performance among the test compounds and only slightly less than the control using (-)-ascorbic acid $\left(\mathrm{EC}_{50}=3.1 \mu \mathrm{g} / \mathrm{ml}\right)$. On the other hand, cinnamaldehyde had the lowest free radical scavenging activity.

\subsection{Antifungal activity of individual compound}

The antifungal activities of test compounds were first examined at the concentration of $100 \mu \mathrm{g} / \mathrm{ml}$, and the results are shown in Table 1. Among all compounds tested, the commercial fungicide, propiconazole, was the most effective and completely inhibited the growth of $L$. betulina and $L$. sulphureus at the concentration of $1 \mu \mathrm{g} /$ $\mathrm{ml}$. Cinnamaldehyde and eugenol also exhibited strong antifungal activities with antifungal index of $100 \%$ against both $L$. betulina and $L$. sulphureus, while catechin and quercetin did not express antifungal activities at the same concentration. The $\mathrm{IC}_{50}$ and $\mathrm{IC}_{90}$ values for individual 
Table 1

Antifungal index $(\%)$ of test compounds against wood decay fungi at the concentration of $100 \mu \mathrm{g} / \mathrm{ml}$

\begin{tabular}{lrc}
\hline Compounds & \multicolumn{1}{l}{ Fungi } \\
\cline { 2 - 3 } & L. betulina & L. sulphureus \\
\hline Cinnamaldehyde & $100 \pm 0.0^{\mathrm{a}}$ & $100 \pm 0.0^{\mathrm{a}}$ \\
Catechin & $3 \pm 1.5^{\mathrm{b}}$ & $5 \pm 1.8^{\mathrm{b}}$ \\
Quercetin & $0 \pm 0.0^{\mathrm{b}}$ & $0 \pm 0.0^{\mathrm{c}}$ \\
Eugenol $_{\text {Propiconazole }^{\mathrm{d}}}$ & $100 \pm 0.0^{\mathrm{a}}$ & $100 \pm 0.0^{\mathrm{a}}$ \\
\hline
\end{tabular}

Results are mean $\pm \mathrm{SE}(n=5)$.

Means in column with different superscript letters are significantly different at alpha level of 0.05 .

${ }^{\mathrm{d}}$ Concentration of propiconazole was $1 \mu \mathrm{g} / \mathrm{ml}$ as a positive control.

compound were further determined, and the results obtained for cinnamaldehyde, eugenol, catechin and quercetin against two wood decay fungi are shown in Table 2. The $\mathrm{IC}_{50}$ values of cinnamaldehyde were 0.65 and $0.23 \mathrm{mM}$ against $L$. betulina and $L$. sulphureus, respectively, and the observations were in accordance with the results reported previously (Wang et al., 2005; Hsu et al., 2007). Among these three antioxidants, only eugenol showed excellent antifungal activities against $L$. betulina and L. sulphureus with $\mathrm{IC}_{50}$ of 0.37 and $0.25 \mathrm{mM}$, respectively. On the contrary, catechin and quercetin revealed very limited inhibitory effects against $L$. betulina and L. sulphureus. As for $\mathrm{IC}_{90}$, the similar results were found that both cinnamaldehyde and eugenol exhibited much stronger antifungal activities against $L$. betulina and L. sulphureus than those of catechin and quercetin. Although catechin and quercetin have been reported to have antifungal effects against Candida albicans (Hirasawa and Takada, 2004), our results clearly indicated that quercetin or catechin alone had almost no antifungal activities against wood decay fungi, and there was also no correlation between the free radical scavenging capabilities and their antifungal properties, indicating that the radical scavenging properties of test compounds might not directly contribute to their antifungal activities.

\subsection{Combined effects of cinnamaldehyde with eugenol, catechin or quercetin}

Cinnamaldehyde combined with natural antioxidants were studied to determine whether the combination of two compounds has synergistic, additive or antagonistic effects against wood decay fungi. The interaction was evaluated by comparing the isoeffective concentrations $\left(\mathrm{IC}_{50}\right.$ and $\mathrm{IC}_{90}$ ) of test compounds and designated combinations. It is considered synergy when the isoeffective concentration of combination was significantly lower than those of compounds acting alone (Tallarida, 2001). Cinnamaldehyde with eugenol, catechin or quercetin were prepared at 1:1 ratio in molarities with serial concentrations for assaying, and the values of $\mathrm{IC}_{50}$ and $\mathrm{IC}_{90}$ were given in Table 2.

Significant synergy was observed on the combination of cinnamaldehyde with eugenol against L. sulphureus. The antifungal index of cinnamaldehyde against L. sulphureus at the concentration of $0.17 \mathrm{mM}$ was $41 \%$, and that of eugenol at the same concentration was $24 \%$, while the antifungal index of combination using cinnamaldehyde and eugenol against L. sulphureus dramatically increased to $90 \%$, indicating portent of synergistic effect. The synergy was further confirmed by comparing their isoeffective concentrations. The values of $\mathrm{IC}_{50}$ and $\mathrm{IC}_{90}$ for the combination of cinnamaldehyde with eugenol against L. sulphureus were 0.18 and $0.37 \mathrm{mM}$, respectively, which were significantly lower than those of using either cinnamaldehyde or eugenol alone. However, only additive effect was found on the combination of cinnamaldehyde and eugenol against $L$. betulina with $\mathrm{IC}_{50}(0.38 \mathrm{mM})$ and $\mathrm{IC}_{90}$ $(0.63 \mathrm{mM})$. In addition, the combinations of cinnamaldehyde with catechin or quercetin against L. sulphureus also exhibited additive effects, but both combinations showed marked antagonistic effects against $L$. betulina. The values of $\mathrm{IC}_{50}$ and $\mathrm{IC}_{90}$ for the combination of cinnamaldehyde with catechin against $L$. betulina were 1.22 and $1.40 \mathrm{mM}$, and against L. sulphureus were 0.23 and $0.52 \mathrm{mM}$, respectively. Among all samples tested, the strongest antagonistic effect was discovered on the combination of cinnamaldehyde and quercetin against $L$. betulina with $\mathrm{IC}_{50}$

Table 2

$\mathrm{IC}_{50}$ and $\mathrm{IC}_{90}$ values of test compounds and in combinations with cinnamaldehyde against wood decay fungi

\begin{tabular}{|c|c|c|c|c|}
\hline \multirow[t]{2}{*}{ Compounds } & \multicolumn{2}{|l|}{ L. betulina } & \multicolumn{2}{|l|}{ L. sulphureus } \\
\hline & $\mathrm{IC}_{50}(\mathrm{mM})$ & $\mathrm{IC}_{90}(\mathrm{mM})$ & $\mathrm{IC}_{50}(\mathrm{mM})$ & $\mathrm{IC}_{90}(\mathrm{mM})$ \\
\hline Cinnamaldehyde & $0.65 \pm 0.03^{\mathrm{b}}$ & $0.72 \pm 0.06^{\mathrm{b}}$ & $0.23 \pm 0.02^{\mathrm{b}}$ & $0.53 \pm 0.02^{\mathrm{b}}$ \\
\hline Eugenol & $0.37 \pm 0.02^{\mathrm{a}}$ & $0.65 \pm 0.05^{\mathrm{a}}$ & $0.25 \pm 0.03^{\mathrm{b}}$ & $0.52 \pm 0.01^{\mathrm{b}}$ \\
\hline Catechin & $>100^{\mathrm{e}}$ & $>100^{\mathrm{e}}$ & $40 \pm 0.12^{\mathrm{c}}$ & $80 \pm 0.14^{\mathrm{c}}$ \\
\hline Quercetin & $>100^{\mathrm{e}}$ & $>100^{\mathrm{e}}$ & $64 \pm 0.25^{\mathrm{d}}$ & $>100^{\mathrm{d}}$ \\
\hline Cin. + eugenol & $0.38 \pm 0.02^{\mathrm{a}}$ & $0.63 \pm 0.04^{\mathrm{a}}$ & $0.18 \pm 0.01^{\mathrm{a}}$ & $0.37 \pm 0.02^{\mathrm{a}}$ \\
\hline Cin. + catechin & $1.22 \pm 0.04^{\mathrm{c}}$ & $1.40 \pm 0.09^{\mathrm{c}}$ & $0.23 \pm 0.04^{\mathrm{b}}$ & $0.52 \pm 0.04^{\mathrm{b}}$ \\
\hline Cin. + quercetin & $1.44 \pm 0.06^{\mathrm{d}}$ & $1.65 \pm 0.07^{\mathrm{d}}$ & $0.26 \pm 0.02^{\mathrm{b}}$ & $0.53 \pm 0.03^{b}$ \\
\hline
\end{tabular}

Results are mean $\pm \mathrm{SE}(n=5)$.

Means in column with different superscript letters are significantly different at alpha level of 0.05 .

Cin.: cinnamaldehyde. 
Table 3

MIC and MFC values of cinnamaldehyde, eugenol and their combination against two wood decay fungi

\begin{tabular}{llllll}
\hline Compounds & \multicolumn{2}{l}{ L. betulina } & & \multicolumn{2}{l}{ L. sulphureus } \\
\cline { 2 - 3 } \cline { 5 - 6 } & MIC $(\mathrm{mM})$ & MFC $(\mathrm{mM})$ & & MIC $(\mathrm{mM})$ & MFC $(\mathrm{mM})$ \\
\hline Cinnamaldehyde & 0.75 & 0.75 & 0.70 & 0.70 \\
Eugenol & 0.70 & 0.70 & 0.65 & 0.65 \\
Cin. + eugenol & 0.68 & 0.68 & 0.40 & 0.40 \\
\hline
\end{tabular}

Cin.: cinnamaldehyde.

$(1.44 \mathrm{mM})$ and $\mathrm{IC}_{90}(1.65 \mathrm{mM})$ which were significantly higher than those of cinnamaldehyde alone.

It was also interesting to see that did the synergistic effects for the combination of cinnamaldehyde and eugenol based on MIC and MFC perform differently to the results based on $\mathrm{IC}_{50}$ and $\mathrm{IC}_{90}$ ? Therefore, the values of MIC and MFC for cinnamaldehyde and eugenol alone, and their combination were determined. The results, as seen in Table 3 , showed that strong synergism was also observed for the combination of cinnamaldehyde and eugenol against L. sulphureus with significantly lower values of MIC $(0.40 \mathrm{mM})$ and MFC $(0.40 \mathrm{mM})$ than that of cinnamaldehyde or eugenol alone. As a result, cinnamaldehyde developed a potent fungicidal activity in combination with subleathal amount of eugenol. However, this combination only revealed additive effect against $L$. betulina with MIC $(0.68 \mathrm{mM})$ and MFC $(0.68 \mathrm{mM})$ which were no different to MIC and MFC values of cinnamaldehyde or eugenol. Furthermore, the same values of MIC and MFC for the combination of cinnamaldehyde with eugenol also showed it was fungicidal instead of fungistatic.

The mechanism of how cinnamaldehyde and eugenol synergistically enhance the antifungal properties of each other remains obscure. Structurally, the fungal cell wall is composed of a complex network of proteins and polycarbohydrates that varies in composition depending on the fungal species. Disrupting this matrix can result in a defective cell wall, which becomes sensitive to osmotic lysis and susceptive to fungicides. Inhibition of fungal cell wall synthesizing enzymes by cinnamaldehyde has been studied by examining the inhibitory effects of cinnamaldehyde on $\beta$ (1,3)-glucan and chitin synthases (Bang et al., 2000). They concluded that cinnamaldehyde is a cell wall active antifungal agent that behaves kinetically as an inhibitor on cell wall synthesis of yeast. As to eugenol, Bennis et al. (2004) studied the surface alternation induced by thymol and eugenol on yeast, and concluded that antifungal activity of eugenol and thymol involve alternations of both membrane and cell wall of yeast.

It is obvious that the both cinnamaldehyde and eugenol inhibit the growth of yeast by either blocking the cell wall synthesis or altering the cell wall structure, resulting in dysfunction of cell wall and increase of permeability to allow foreign particles entering fungal cell causing yeast death. The antifungal mechanisms of cinnamaldehyde and eugenol in wood decay fungi are very possible performing in the same way as they do in the yeast. Any action on the destruction of fungal cell wall and membrane can be considered to be additive for their antifungal activity. Therefore, the reasonable explanation for the synergy of cinnamaldehyde with eugenol against $L$. sulphureus could be that eugenol alters the surface and structure of fungal cell wall, and cinnamaldehyde acts as a potentiator by reducing the cell wall synthesis and facilitating the leakage of fungal cytoplasm. In addition to the combining actions induced by cinnamaldehyde and eugenol, the radical scavenging activity of eugenol might also further accelerate the fungal death by scavenging the radicals produced by fungus, and reduce fungal nutrition uptake for repairing cell wall injury, resulting in the strong synergy of antifungal activity.

\section{Conclusions}

From the results, it could be concluded that the combination of cinnamaldehyde with eugenol showed excellent antifungal properties, and strong synergy was also observed against $L$. sulphureus on the basis of $\mathrm{IC}_{50}, \mathrm{IC}_{90}$, MIC or MFC. The synergistic effect of cinnamaldehyde with eugenol could be attributed to the integrated actions of cell wall alteration, interference of cell wall synthesis, and the addition of radical scavenging. It also suggested that antioxidant with fungicidal effect might be a better candidate than pure antioxidant for the system of fungicide/antioxidant.

\section{Acknowledgement}

Funding for this study was provided by the National Science Council of Taiwan (NSC-93-2313-B-002-014).

\section{References}

Bang, K.H., Lee, D.W., Park, H.M., Rhee, Y.H., 2000. Inhibition of fungal cell wall synthesizing enzymes by trans-cinnamaldehyde. Biosci. Biotechnol. Biochem. 64, 1061-1063.

Bennis, S., Chami, F., Chami, N., Bouchikhi, T., Remmal, A., 2004. Surface alteration of Saccharomyces cerevisiae induced by thymol and eugenol. Lett. Appl. Microbiol. 38, 454-458.

Chang, S.T., Wang, S.Y., Wu, C.L., Chen, P.F., Kuo, Y.H., 2000. Comparison of the antifungal activity of cadinane skeletal sesquiterpenoids from Taiwania (Taiwania cryptomerioides Hayata) heartwood. Holzforschung 54, 241-245.

Cheng, S.S., Liu, J.Y., Hsui, Y.R., Chang, S.T., 2006. Chemical polymorphism and antifungal activity of essential oils from leaves of different provenances of indigenous cinnamon (Cinnamomum osmophloeum). Bioresour. Technol. 97, 306-312.

Guo, J.T., Lee, H.L., Chiang, S.H., Lin, F., Chang, C.Y., 2001. Antioxidant properties of the extracts from different parts of Broccoli in Taiwan. J. Food Drug Anal. 9, 96-101.

Hirasawa, M., Takada, K., 2004. Multiple effects of green tea catechin on the antifungal activity of antimycotics against Candida albicans. J. Antimicrob. Chemother. 53, 225-229.

Hsu, F.L., Chang, H.T., Chang, S.T., 2007. Evaluation of antifungal properties of octyl gallate and its synergy with cinnamaldehyde. Bioresour. Technol. 98, 734-738.

Kubo, I., Lee, S.H., 1998. Potentiation of antifungal activity of sorbic acid. J. Agric. Food Chem. 46, 4052-4055. 
Mabicka, A., Dumarcy, S., Rouhier, N., Linder, M., Jacquot, J.P., 2005. Synergistic wood preservatives involving EDTA, irganox 1076 and 2hydroxypyridine- $N$-oxide. Int. Biodeterior. Biodegrad. 55, 203-211.

Schultz, T.P., Nicholas, D.D., 2000. Naturally durable heartwood: evidence for a proposed dual defensive function of the extractives. Phytochemistry 54, 47-52.

Schultz, T.P., Nicholas, D.D., 2002. Development of environmentallybenign wood preservatives based on the combination of organic biocides with antioxidants and metal chelators. Phytochemistry 61, $555-560$.

Tallarida, R.J., 2001. Drug synergism: its detection and applications. J. Pharmacol. Exp. Ther. 298, 865-872.

Wang, S.Y., Chen, P.F., Chang, S.T., 2005. Antifungal activities of essential oils and their constituents from indigenous cinnamon (Cinnamomum osmophloeum) leaves against wood decay fungi. Bioresour. Technol. 96, 813-818. 